\title{
Diagênese, contexto deposicional e história de soterramento da Formação Rio Bonito, Bacia do Paraná
}

\author{
Luciane Bergamin Bocardi ${ }^{1}$, Sidnei Pires Rostirolla ${ }^{2}$, Fernando Farias Vesely ${ }^{3}$ \\ \& Almério Barros França ${ }^{4}$
}

\begin{abstract}
Resumo A análise de subsidência e processos diagenéticos que atuaram sobre os arenitos da Formação Rio Bonito foram realizados com base em poços selecionados na Bacia do Paraná. Entre os principais constituintes eodiagenéticos destaca-se a ocorrência de pirita, calcita, siderita e caolinita, os quais apresentam variação na quantidade e distribuição, de acordo com as fácies deposicionais, limites de paraseqüências e tratos de sistemas. Os principais produtos relacionados à mesodiagênese foram anquerita, clorita, crescimentos sintaxiais de quartzo e illita. A correlação entre o controle da distribuição dos constituintes mesodiagenéticos e as seqüências deposicionais nem sempre pode ser estabelecido. Porém a cimentação por quartzo nesse estágio, pode ser influenciada pela distribuição das alterações eodiagenéticas em arenitos constituídos essencialmente por quartzo, com pouca influência de cimentação carbonática. Nos poços analisados a profundidade máxima de soterramento da Formação Rio Bonito foi de aproximadamente $4000 \mathrm{~m}$, que corresponde à temperatura próxima a $120^{\circ} \mathrm{C}$. Estas condições implicam em modificações mesodiagenéticas, tais como compactação química, reações de transformação de argilominerais e cimentação de quartzo. Com a modelagem da história de soterramento, considerando a idade, seleção e profundidade, os resultados obtidos evidenciam que a porosidade na profundidade de $3.000 \mathrm{~m}$ de soterramento situa-se em torno de $20 \%$. Por outro lado observa-se grande variação na porosidade de acordo com as fácies deposicionais. Em geral, a compactação foi mais importante que a cimentação, na redução da porosidade porém, a cimentação eodiagenética foi um fator positivo na preservação do arcabouço dos arenitos.
\end{abstract}

Palavras-chave: Diagênese, história de soterramento, Formação Rio Bonito.

\begin{abstract}
Diagenesis, depositional setting and burial history of the Rio Bonito Formation, Paraná Basin. Subsidence analysis and diagenetic processes in the sandstones of the Rio Bonito Formation was based on wells drilled in the Paraná Basin. The main eodiagenetics products are pyrite, calcite, siderite and kaolinite. The main diagenetics products related to mesodiagenesis of the Rio Bonito Formation are ankerite, chlorite, quartz overgrowths and illita. The correlation between diagenetc products and sequence stratigraphy can not always be established. However, quartz overgrowths in the mesodiagenesis can be influenced by eodiagenetic alterations in quartzarenites with little influence of carbonatic cementation. In the analyzed wells the maximum burial depth of the Rio Bonito Formation was approximately $4000 \mathrm{~m}$ and corresponds to temperature around $120^{\circ} \mathrm{C}$. These conditions imply in mesodiagenetics modifications, such as chemical compacting, clay mineral transformation reactions and quartz overgrowths. With the burial history modeling and considering the age, selection and depth, the Rio Bonito Formation sandstones has porosity around 20\% in burial depth of $3.000 \mathrm{~m}$. This indicates that despite the high burial depth, the sandstones might have good porosity, depending on depositional conditions. In general, compacting was more important than cementation, in reducing porosity. However, the eodiagenetic cementation was a positive factor in the sandstones framework preservation.
\end{abstract}

Keywords: Diagenesis, burial history, Rio Bonito Formation.

INTRODUÇÃO A porosidade e permeabilidade das rochas siliciclásticas são controladas principalmente por processos diagenéticos. A compreensão destes processos auxilia na avaliação do potencial para armazenamento de fluidos nessas rochas.

Os depósitos costeiros e marinhos relacionados à Formação Rio Bonito são tradicionalmente considerados bons reservatórios de hidrocarbonetos por apresen- tarem características permoporosas satisfatórias, mesmo em grandes profundidades de soterramento. Porém, os controles da heterogeneidade dos reservatórios são pouco conhecidos. A integração dos aspectos diagenéticos com contexto deposicional refere-se ao estudo das alterações que ocorrem próximas à superfície, durante o estágio eodiagenético. No estágio mesodiagenético a diagênese é influenciada pela história de soterramento

1 - PETROBRAS - UN-RIO/EXP e UFPR - Doutoranda em Geologia Exploratória, Curitiba (PR), Brasil. E-mail: lbocardi@gmail.com

2 - UFPR, Professor Associado e Bolsista de Produtividade do CNPq - Departamento de Geologia, Curitiba (PR), Brasil. E-mail: sidnei. rostirolla@vale-ep.com

3 - PETROBRAS - E\&P-EXP/GEO/Estratigrafia e Sedimentologia, Rio de Janeiro (RJ), Brasil. E-mail: vesely@petrobras.com.br

4 - PETROBRAS - CENPES/PDEXP/GSEP. E-mail: almeriobfranca@petrobras.com.br 
da bacia. Os controles que interferem na porosidade e permeabilidade das rochas siliciclásticas dependem, da interação de vários fatores atuantes durante a evolução da bacia, principalmente em unidades mais antigas. $\mathrm{O}$ principal objetivo deste estudo é a interpretação da seqüência dos processos diagenéticos que atuaram nos arenitos que constituem a Formação Rio Bonito, de acordo com o contexto deposicional e a história de subsidência e soerguimento atuantes na Bacia do Paraná.

MÉTODOS Foram amostrados afloramentos e teste- munhos de sondagens rasas de áreas próximas ao município de Ibaiti no Estado do Paraná e testemunhos de sondagem provenientes de poços profundos da Bacia do Paraná (Fig. 1). As descrições de fácies realizadas em afloramentos e testemunhos na região nordeste do estado do Paraná, apresentadas por Zacarias (2004), bem como trabalhos prévios com enfoque à estratigrafia da Formação Rio Bonito foram utilizadas para correlação com poços profundos da Bacia do Paraná a fim de subsidiar a amostragem em subsuperfície. Foram analisadas 45 amostras coletadas em afloramentos, 20 amostras de

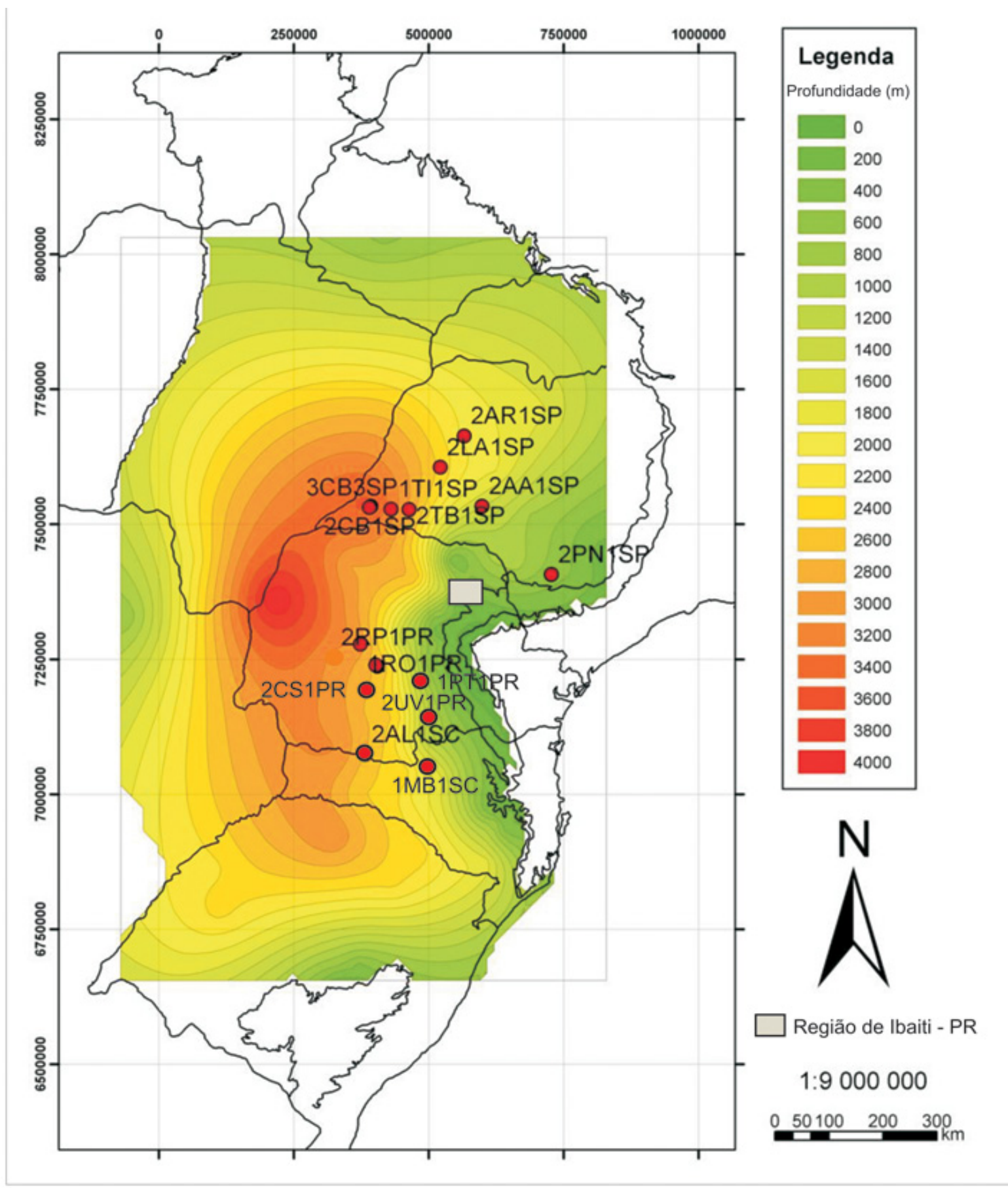

Figura 1 - Profundidade da Formação Rio Bonito na Bacia do Paraná, com a localização dos poços estudados. 
testemunhos de sondagens rasas e 30 amostras selecionadas em intervalos de profundidade entre 886 e $2655 \mathrm{~m}$ nos poços da Bacia do Paraná (Figs. 1 e 2).

As amostras foram impregnadas com resina e corante azul e os constituintes detríticos, diagenéticos e percentual de poros foram determinados por contagem de 300 pontos em seções delgadas. A determinação da porosidade foi realizada pela análise digital de imagens, com base em Ehrlich et al. (1984) e Anjos (1995) e por meio de perfis sônico. A porosidade original foi estimada a partir das características texturais de seleção dos grãos, conforme Beard \& Weyl (1973). Os constituintes diagenéticos foram identificados com microscópio óptico de luz transmitida com câmera para captura de imagens digitais. Os argilominerais foram analisados por difração de raios $\mathrm{X}$, com difratômetro Philips $\mathrm{PW}$ 1830. A morfologia e relações entre os minerais foram examinadas com microscópio eletrônico de varredura (Philips XL30) e interpretadas conforme SEM Petrology Atlas (Welton 1984). A importância relativa dos processos de compactação e cimentação na redução da porosidade foi analisada usando-se gráficos de volume intergranular versus cimentação (Houseknecht, 1987).

A estimativa da história de soterramento foi realizada a partir da integração de dados geológicos procedentes de estudos realizados na Bacia do Paraná, com a utilização de programa computacional para modelagem de bacias, aplicado à avaliação de sistemas petrolíferos (BasinMod 1D).

ARCABOUÇO ESTRATIGRÁFICO A Bacia do Paraná (Fig. 1) localiza-se na porção centro-sul da América do Sul, com abrangência territorial de 1.600 .000 $\mathrm{km}^{2}$, distribuída entre o Brasil, Argentina, Uruguai e Paraguai. É constituída por uma sucessão sedimentarmagmática com idades entre o Neo-Ordoviciano (465 Ma) e o Neocretáceo (65 Ma) e uma história geológica marcada por eventos cíclicos, de subsidência e soerguimento. Estes eventos relacionam-se ao desenvolvimento de superseqüências limitadas por discordâncias regionais. Neste contexto, seis unidades de segunda ordem compõem seu arcabouço estratigráfico, denominadas Superseqüência Rio Ivaí, Superseqüência Paraná, Superseqüência Gondwana I, Superseqüência Gondwana II, Superseqüência Gondwana III e Superseqüência Bauru (Milani, 1997).

A Formação Rio Bonito faz parte da Supersequência Gondwana I (Fig. 3), que representa amplo registro sedimentar da bacia, com espessuras na ordem de 2500 metros. Sua história sedimentar tem início com a subsidência do Carbonífero, acompanhada pela deposição das unidades Aquidauana-Itararé, com registros sedimentares de até 1500 metros espessura. Sobrepostos ao Grupo Itararé, ocorrem arenitos, siltitos e camadas de carvão da Formação Rio Bonito. A deposição do Grupo Itararé e da Formação Rio Bonito foi influenciada inicialmente pela fase de subsidência atribuída à sobrecarga das geleiras continentais, seguida pelo peso dos sedimentos depositados durante o ciclo transgressivo-regressivo subseqüente (Zalán et al. 1987).

No Mesozóico, a Bacia do Paraná foi submetida a um período de quiescência tectônica prolongada, interrompido por movimentos de reativação e ruptura do Gondwana, no início do Cretáceo.

O contato entre as formações Rio do Rasto / Pi-

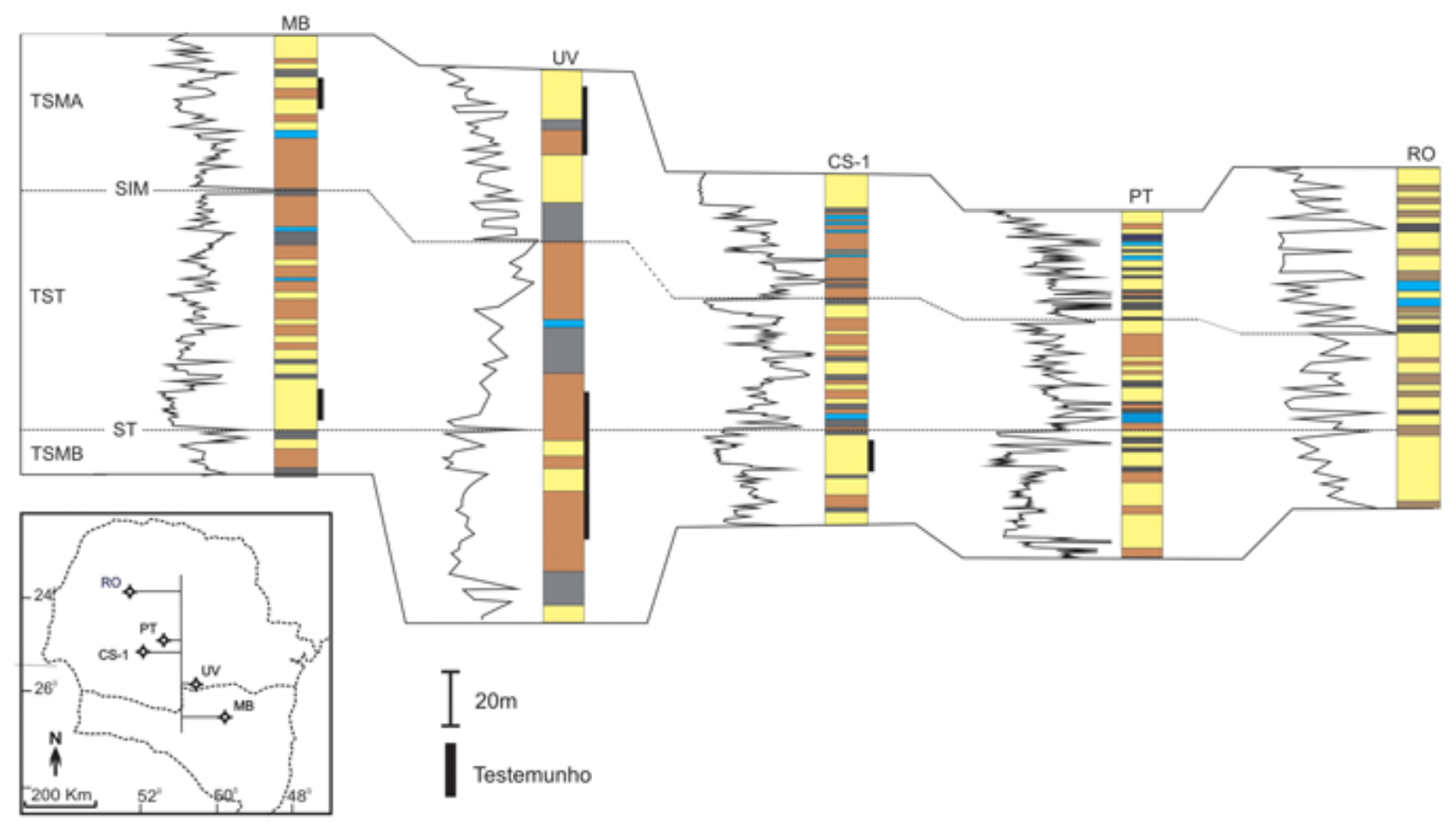

Figura 2 - Correlação da Fm. Rio Bonito com base em poços realizados na Bacia do Paraná, com indicação dos testemunhos utilizados. 


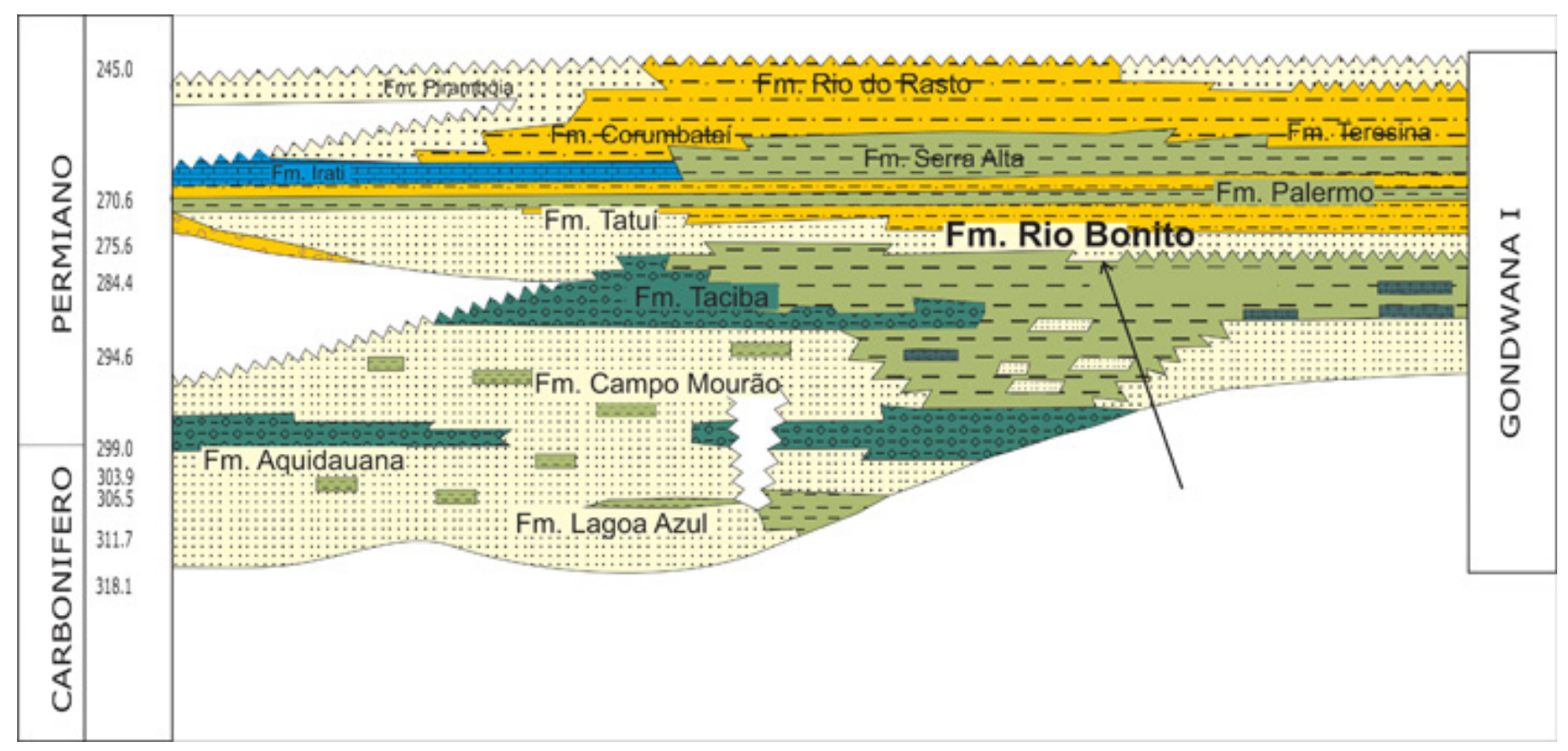

Figura 3 - Carta estratigráfica com as unidades do Carbonífero e Permiano da Bacia do Paraná com destaque à Fm. Rio Bonito (adaptada de Milani 2004).

rambóia e Botucatu consiste em discordância erosiva com um hiato deposicional de aproximadamente $100 \mathrm{Ma}$ de duração. O rifteamento sul-atlantiano responsável pela ruptura do Gondwana ocidental envolveu o embasamento da bacia. Suturas antigas foram reativadas seguidas pela geração de novos conjuntos de falhas e fraturas, que propiciaram a injeção e o extravasamento de grandes volumes de rochas ígneas, com espessura próxima a 2000 metros, no depocentro. A Superseqüência Bauru (Milani, 1997), constituída essencialmente por arenitos continentais, com espessura da ordem de 300 metros, assenta em discordância sobre os basaltos Serra Geral e completa o preenchimento da Bacia do Paraná.

Na porção Leste da Bacia do Paraná, a Formação Rio Bonito foi dividida em membros denominados Triunfo, Paraguaçu e Siderópolis por Schneider et al. 1974. O Membro Triunfo, base da unidade, constituise de arenitos finos a médios e grossos, com estratificações cruzadas, grãos subarredondados e seleção moderada. Siltitos e carvão ocorrem intercalados. Schneider et al. 1974 interpretaram esta unidade como sendo flúvio-deltaica. O Membro Paraguaçu representa a porção média da formação, com camadas de siltitos e folhelhos intercaladas com arenitos finos e rochas carbonáticas. A sedimentação desta unidade ocorreu em condições marinhas transgressivas. O Membro Siderópolis, topo da unidade, é constituído de camadas de arenito fino a muito fino intercalados com folhelhos carbonosos e carvão. Condições litorâneas progradantes influenciaram a deposição desta unidade. Segundo Medeiros e Thomaz $\mathrm{F}^{\circ}$ (1973), as fácies carbonosas originadas em lagunas ou mangues foram recobertas por areias litorâneas.

Em estudos recentes, o intervalo Eo-Permiano da Bacia do Paraná tem sido abordado com enfoque à estratigrafia de seqüências (Lopez \& Lavina 2001, Holz et al. 2002, Holz 1998, 1999, 2003, Zacharias 2004). O Eo-Permiano da Bacia do Paraná foi um período de transgressões marinhas relacionados ao aumento relativo no nível do mar num contexto de $2^{\mathrm{a}}$ ordem, com transgressão da linha de costa e curtos episódios regressivos, que caracterizam eventos de $3^{\text {a }}$ ordem (Zalán et al. 1990). Holz (2003) propôs um arcabouço estratigráfico regional de terceira ordem para a Formação Rio Bonito na região sul do Brasil. O arcabouço estratigráfico proposto inclui depósitos flúvio-deltaicos e depósitos associados à pântanos, com camadas de carvão intercaladas seguido de depósitos influenciados por condições costeiras. No modelo apresentado por Zacharias (2004), a deposição inicial da Formação Rio Bonito é relacionada ao preenchimento de vales incisos e desenvolvimento de um sistema estuarino e culmina com depósitos marinhos rasos.

A Formação Rio Bonito representa uma seqüência deposicional de terceira ordem, formada pelos tratos de sistema de mar baixo, tratos de sistema transgressivo e tratos de sistema mar alto (Holz 1998, 2002, 2003; Zacarias 2004). Na região nordeste do estado do Paraná, Zacarias (2004) identificou as Associações de Fácies 1 e 2, relacionadas ao Membro Triunfo, depositadas durante o trato de sistemas de mar baixo. As Associação de Fácies 3 e 4 correspondem ao Membro Paraguaçu, depositadas durante o trato de sistema transgressivo e mar alto. O Membro Siderópolis corresponde à Associação de Fácies 5 depositada durante o trato de sistema de mar alto.

COMPOSIÇÃO DETRÍTICA Os arenitos que compõem as principais fácies deposicionais foram classificados de acordo com Folk (1968) (Tab. 1 e Fig. 4). Os arenitos da associação de fácies 1, que representam os depó- 
Tabela 1 - Associações de fácies, características litológicas, contexto deposicional, tratos de sistema e classificação dos arenitos com base no conteúdo detrítico segundo Folk (1968).

\begin{tabular}{|c|c|c|c|c|}
\hline Associações de fácies & $\begin{array}{l}\text { Características } \\
\text { litológicas }\end{array}$ & Contexto deposicional & Tratos de sistema & Classificação \\
\hline Associação de fácies 1 e 2 & $\begin{array}{l}\text { Arenitos feldspáticos } \\
\text { finos a grossos. }\end{array}$ & $\begin{array}{l}\text { Depósitos iniciais de } \\
\text { preenchimento de vales } \\
\text { incisos. }\end{array}$ & TSMB & Subarcóseos \\
\hline Associação de fácies 3 . & $\begin{array}{l}\text { Arenitos finos } \\
\text { a grossos e } \\
\text { conglomeráticos } \\
\text { como drapes de argila. }\end{array}$ & $\begin{array}{l}\text { Depósitos de canais de } \\
\text { maré, canais fluviais e } \\
\text { ilhas barreiras. }\end{array}$ & TST & Subarcóseos \\
\hline $\begin{array}{l}\text { Porção inferior da } \\
\text { Associação de fácies } 4 .\end{array}$ & $\begin{array}{l}\text { Arenitos finos a } \\
\text { médios }\end{array}$ & $\begin{array}{l}\text { Depósitos de barras de } \\
\text { desembocadura, ilhas } \\
\text { barreiras e deltas de } \\
\text { maré de enchente. }\end{array}$ & TST & $\begin{array}{l}\text { Subarcóseos } \\
\text { Quartzoarenitos }\end{array}$ \\
\hline $\begin{array}{l}\text { Porção superior da } \\
\text { Associação de fácies } 4 \text { e } \\
\text { Associação de fácies } 5 \text {. }\end{array}$ & $\begin{array}{l}\text { Arenitos médios } \\
\text { a finos, bem } \\
\text { selecionados. }\end{array}$ & $\begin{array}{l}\text { Depósitos marinho } \\
\text { rasos de plataforma e } \\
\text { barras litorâneas. }\end{array}$ & TSMA & $\begin{array}{l}\text { Subarcóseos } \\
\text { Quartzoarenitos }\end{array}$ \\
\hline
\end{tabular}

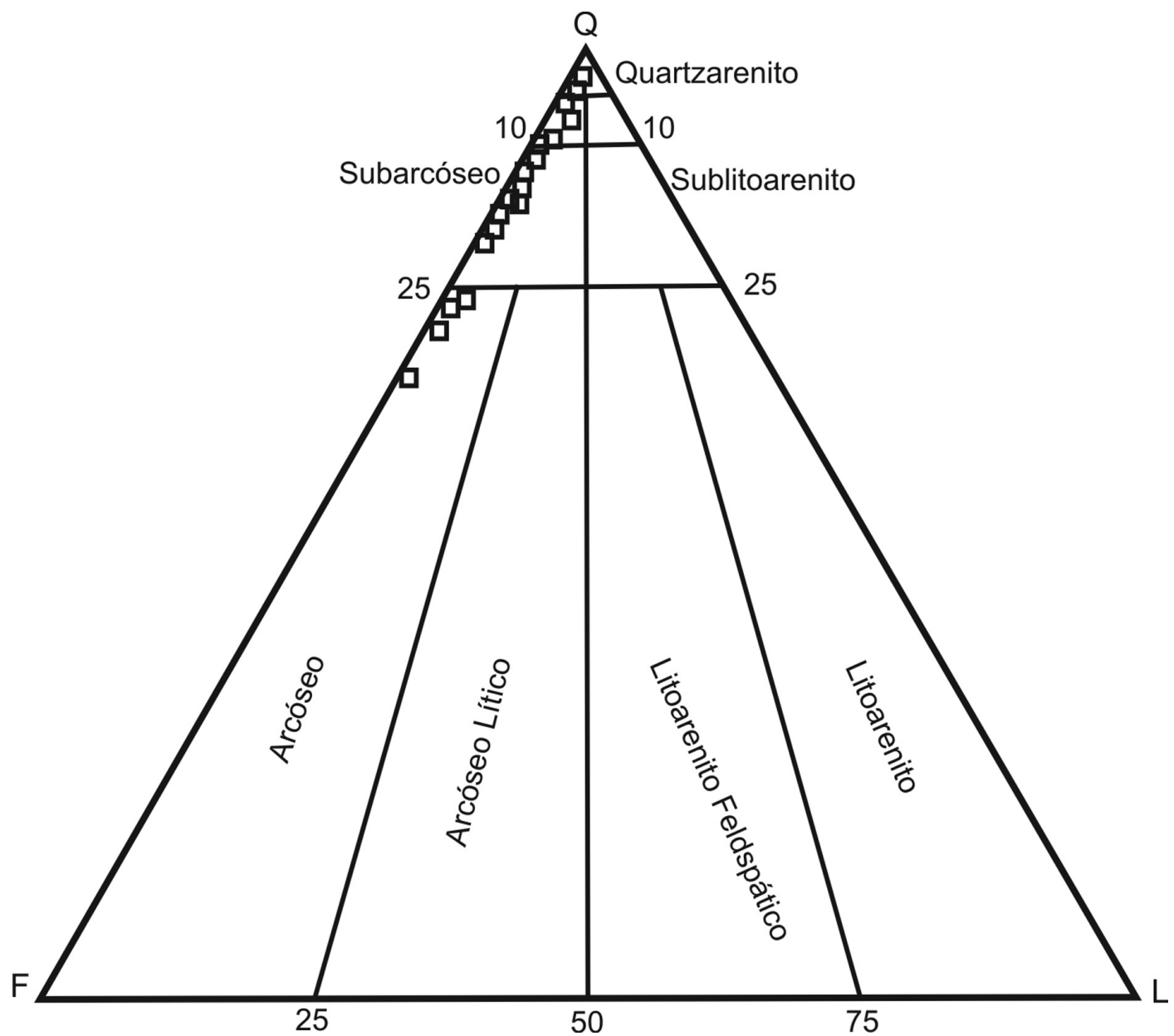

Figura 4 - Composição detrítica dos arenitos da Fm. Rio Bonito. Diagrama modificado de Folk (1968). $Q=$ =quartzo; $F=$ feldspato; $L=$ fragmentos líticos. 
sitos iniciais do preenchimento de vale inciso do trato de sistemas de mar baixo (TSMB) e os arenitos estuarinos das associações de fácies 2,3 , e base associação de fácies 4, depositados durante o trato de sistemas transgressivo (TST) são predominantemente subarcóseos. Os arenitos que constituem a porção inferior da associação de fácies 4 do trato de sistemas transgressivo (TST) e os arenitos que compõem a porção superior da associação de fácies 4 e a associação de fácies 5 depositados sob influência de sistemas costeiros (foreshore e shoreface), durante o trato de sistemas de mar alto (TSMA), são classificados como subarcóseos e quartzoarenitos.

\section{CONSTITUINTES DIAGENÉTICOS}

Eodiagênese A distribuição das alterações eodiagenéticas tais como dissolução de grãos, cimentação por pirita, calcita, siderita e caolinita são relacionadas às seqüências deposicionais.

PIRITA Ocorre na forma de agregados irregulares ou como agregados framboidais. Agregados de pirita substituem frequentemente grãos detríticos de quartzo, feldspatos e clastos argilosos. Concreções de pirita podem ocorrer ao longo de camadas em arenitos associados ao trato de sistemas transgressivos. Nos arenitos depositados durante o trato de sistema transgressivo a formação de pirita, relaciona-se principalmente aos limites de paraseqüência, superfícies transgressivas e superfície de inundação máxima. Ocorrem preferencialmente nos limites de paraseqüências próximo a camadas de carvão.

CALCITA É o principal constituinte diagenético dos arenitos da Formação Rio Bonito (Fig. 5). Ocorre prin- cipalmente preenchendo poros intergranulares com hábito microcristalino e poiquilotópico, com evidências de duas fases principais de precipitação. Outra forma de ocorrência é por substituição parcial de grãos detríticos de quartzo, feldspato, clastos argilosos e caolinita. A relação entre a cimentação por calcita e pirita sugere que a precipitação desses constituintes foi contemporânea. Calcita ocorre na maioria das fácies e tratos de sistemas, mas é relacionada principalmente a camadas de carvão, que ocorrem nos limites de parasseqüências. A relação da cimentação por calcita com os demais constituintes diagenéticos sugere que a precipitação iniciou sob soterramento raso, indicado pela calcita com textura microcistalina. Cristais poiquilotópicos, típicos condições de temperatura mais elevada, indicam que a cimentação por calcita continuou até a mesodiagênese. A distinção entre a calcita precipitada durante a eodiagênese e a mesodiagênese nem sempre é possível, uma vez que a textura é similar. Os níveis cimentados por calcita, em limites de paraseqüência podem ser identificados em perfis geofísicos por apresentarem picos de resistividade mais elevada que as porções adjacentes.

SIDERITA Pode ocorrer com hábito microcristalino e na forma de cristais romboédricos preenchendo poros intergranulares frequentemente em contato com os grãos de quartzo detrítico (Fig. 5). Também substitui grãos detríticos, clastos argilosos e pseudomatriz. Cristais romboédricos de siderita, bem desenvolvidos preenchem poros de arenitos pouco compactados. Feições de dissolução e oxidação são freqüentes. Nos arenitos que compõem o trato de sistemas transgressivo e trato de sistemas de mar alto a formação de siderita ocorre
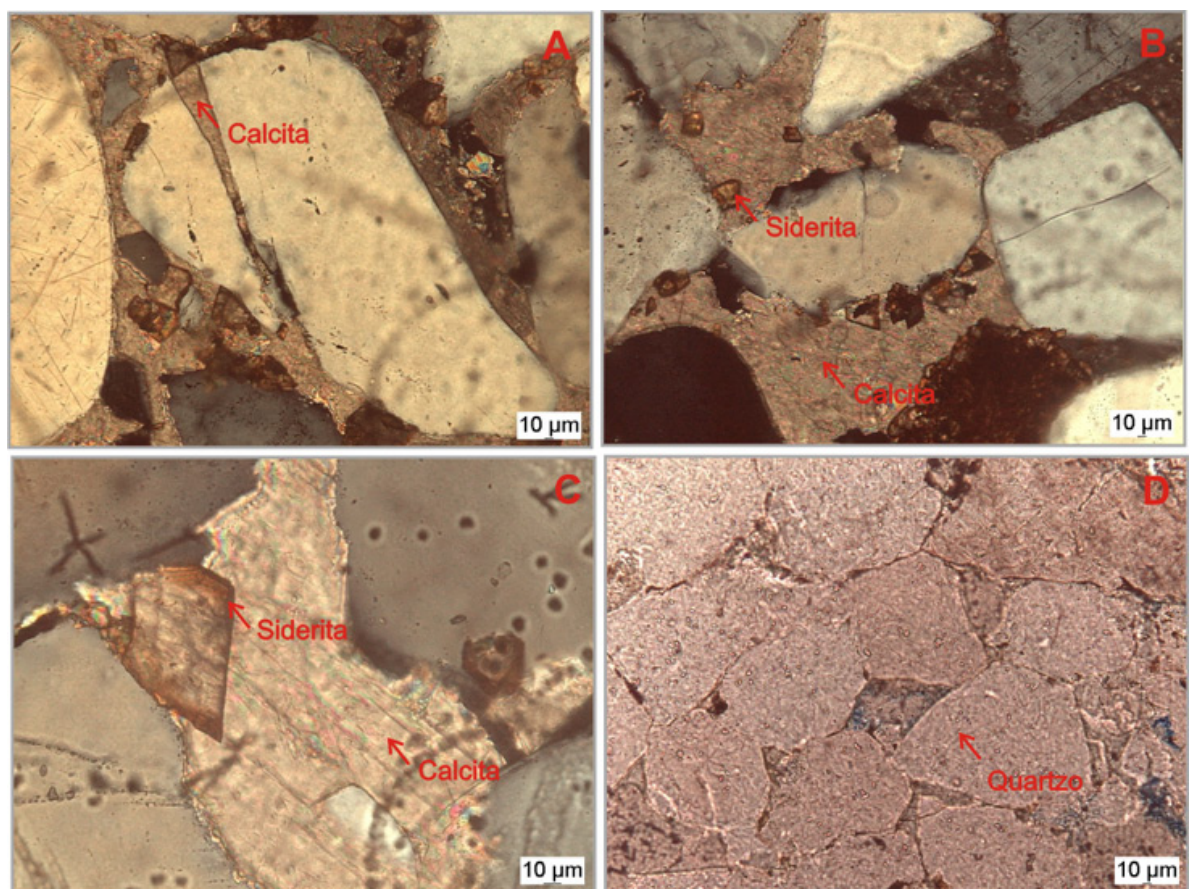

Figura 5 - A-Fratura em grão de quartzo preenchida por calcita; $B$ e CCalcita e Siderita; D - Crescimentos sintaxiais de quartzo. 
principalmente próximo aos limites de paraseqüência, superfícies transgressivas e superfície de inundação máxima. Condições subóxicas em sedimentos marinhos, condicionadas pelas baixas taxas de sedimentação em limites de paraseqüências e superfícies transgressivas facilitam a precipitação de siderita.

CAOLINITA Ocorre como agregados vermiculares que preenchem poros intergranulares e substituem micas, pseudomatriz e feldspatos detríticos. A ocorrência de caolinita é abundante em depósitos de preenchimento de vales incisos, representados pela associação de fácies 1 , do trato de sistemas de mar baixo. Condições climáticas úmidas durante a deposição favorecem o fluxo de fluidos meteóricos que promovem a dissolução de feldspatos, micas e fragmentos líticos associada a formação da caolinita. Nos arenitos que compõem o trato de sistemas transgressivo e trato de sistemas de mar alto, a formação caolinita ocorre principalmente próximo aos limites de paraseqüência, superfícies transgressivas e superfície de inundação máxima.

Mesodiagênese Os principais produtos diagenéticos relacionados à mesodiagênese foram anquerita, clorita, crescimentos sintaxiais de quartzo e illita. A correlação entre o controle da distribuição desses constituintes e as seqüências deposicionais nem sempre pode ser estabelecida. Porém a cimentação por quartzo no estágio mesodiagenético pode ser controlada pela distribuição das alterações eodiagenéticas em arenitos constituídos essencialmente por quartzo, com pouca influência de cimentação carbonática, depositados sob condições marinha rasas (Morad et al. 2000).

ANQUERITA Em amostras de arenitos de intervalos de profundidade em torno de $2300 \mathrm{~m}$, a presença de anquerita é freqüente porém, não foi possível correlacionar a sua distribuição com os tratos de sistema deposicionais. Ocorre sob a forma de grandes cristais, comumente poiquilotópicos, preenchendo poros intergranulares (Figs. 6C e D). As relações paragenéticas observadas sugerem que a precipitação de anquerita relaciona-se a uma fase diagenética tardia. Estudos relacionam a precipitação de anquerita com o soterramento efetivo sob temperatura superior a $130^{\circ} \mathrm{C}$, característica do estágio mesodiagenético. Schmid et al. (2003) verificou que a precipitação de anquerita, em arenitos triássicos relaciona-se à temperatura entre 135 a $145^{\circ} \mathrm{C}$ em um sistema isoquímico.

CLORITA Ocorre como revestimento da superfície de grãos detríticos, formando arranjos perpendiculares ou como agregados preenchendo poros intergranulares (Figs. 6A, 6C e D). A clorita que ocorre em poros intergranulares relaciona-se a substituição principalmente de minerais micáceos, em particular de biotitas. Observada sob microscopia eletrônica de varredura (MEV), a clorita aparece como cristais em forma de placas, característica de cloritas com maiores concentrações em ferro que passam gradualmente a interestratificados
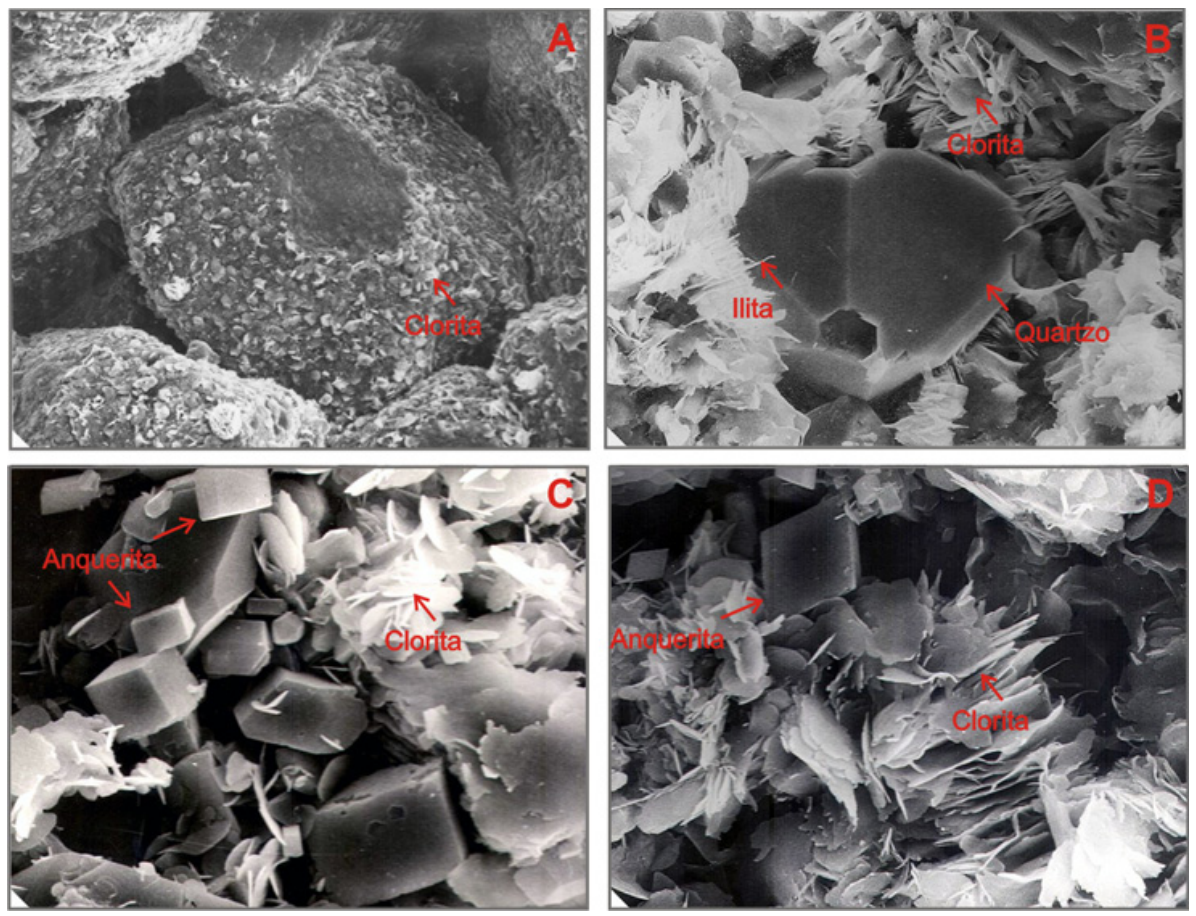

Figura 6 - A - Clorita na superficie de grão de quartzo. B - Crescimento sintaxial de quartzo, aparentemente posterior à formação de clorita e contemporâneo à formação de ilita. C-Clorita e romboedros de anquerita. $D$ - Clorita ilitizada e romboedros de anquerita. 
clorita-ilita e ilitas (Fig. 6D). A formação de clorita é atribuída à transformação de argilas ricas em ferro durante a mesodiagênese.

QUARTZO Caracteriza-se por crescimentos sintaxiais bem desenvolvidos em torno dos grãos detríticos de quartzo (Fig. 6B). Sua distribuição é bastante heterogênea e chega a atingir valores de até $15 \%$ em arenitos bem selecionados, depositados sob condições costeiras durante o trato de sistemas de mar alto, relacionados à porção superior da associação de fácies 4 e associação de fácies 5 . A dissolução por pressão intergranular entre grãos de quartzo em arenitos bem selecionados, com pouca influência de cimentação carbonática precoce, provavelmente favoreceu a cimentação por crescimentos sintaxiais de quartzo.

ILITA Ilita e a ilita/esmectita revestem freqüentemente grãos detríticos na forma de franjas que exibem orientações perpendiculares à superfície dos grãos detríticos (Figs. 6B, C e D). Em amostras provenientes de intervalos de profundidade superiores a $2.000 \mathrm{~m}$, ilita é observada com freqüência, porém a correlação entre a sua distribuição e os tratos de sistema deposicionais não foi possível. De acordo com Morad et al. (2000), ilita e ilita/esmectita formam-se na mesodiagênese, por substituição de argilas infiltradas e intraclastos argilosos. A precipitação de ilita autigênica na mesodiagênese é favorecida pela reação isoquímica entre caolinita e feldspato potássico, sob alta temperatura e condições de soterramento profundo (Bjørkum \& Gjelsvik 1988).

HISTÓRIA DE SOTERRAMENTO E ESTÁGIOS DIAGENÉTICOS Quatro principais fases de subsidência ocorreram na Bacia do Paraná (Figs. 7 e 8). A primeira fase é marcada pela deposição da seqüência Rio Ivaí (Ordoviciano), relacionada ao início da sedimentação da bacia. Após este estágio, há um hiato de aproximadamente $12 \mathrm{Ma}$. A segunda fase de subsidência, no Devoniano, marca a deposição da Seqüência Paraná, constituída pelas formações Furnas e Ponta Grossa. Após este período e a deposição da próxima seqüência há uma superfície discordante com hiato de aproximadamente 50Ma. A terceira fase de subsidência do Permocarbonífero ao início do Triássico, relacionase a deposição de cerca de $2.400 \mathrm{~m}$ de sedimentos da Seqüência Gondwana I. A partir do Permiano inicia a história de soterramento da Formação Rio Bonito. Após esta fase de subsidência houve um período de exposição e erosão com duração em torno de $100 \mathrm{Ma}$. Do Neojurássico ao Eocretáceo ocorre a quarta fase de subsidência da bacia, sob influência da sobrecarga exercida pela magmatismo basáltico. Esta subsidência acentuada exerceu grande influência na história de soterramento da Formação Rio Bonito. Após o magmatismo destacase a deposição da Seqüência Bauru.

A Formação Rio Bonito apresenta espessura

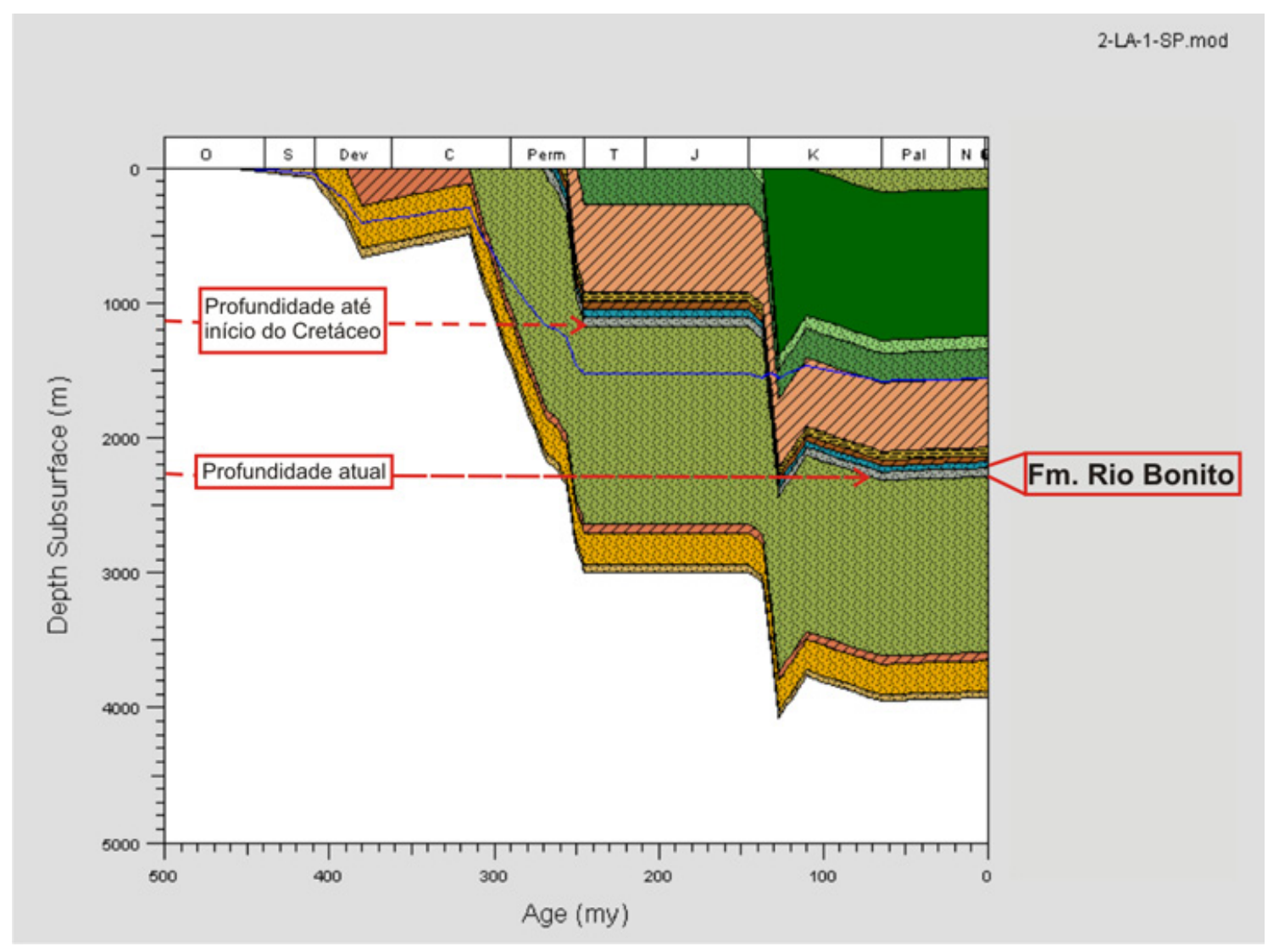

Figura 7 - História de soterramento da Bacia do Paraná com ênfase no soterramento da Formação Rio Bonito no Poço 2-LA-1-SP. 


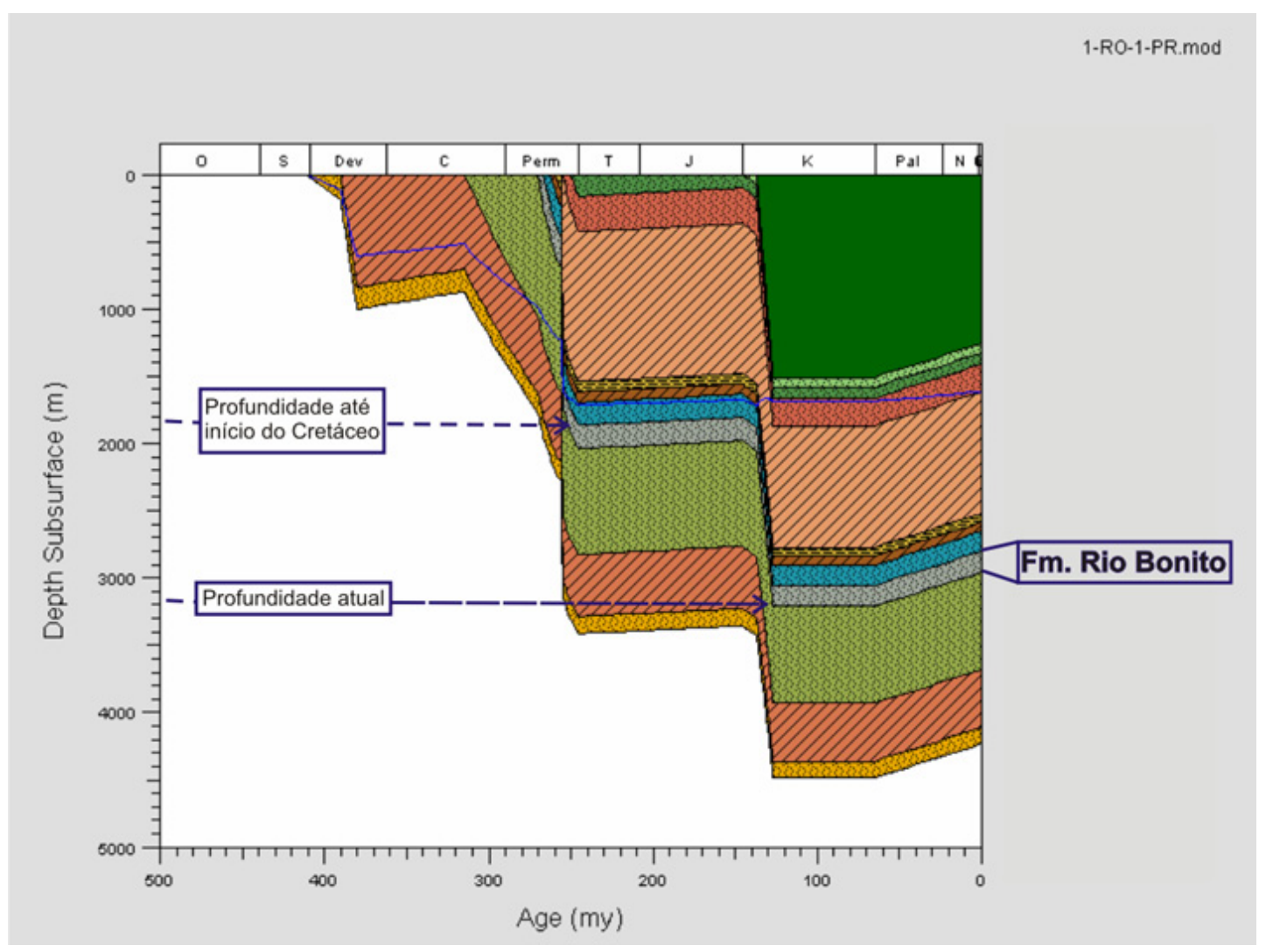

Figura 8 - História de soterramento da Bacia do Paraná com ênfase no soterramento da Formação Rio Bonito no Poço 1-RO-1-PR.

máxima de aproximadamente $260 \mathrm{~m}$ e profundidade de soterramento em torno de $3000 \mathrm{~m}$, mas pode chegar até $4000 \mathrm{~m}$ no depocentro (Fig. 1). Com os dados do poço 2-LA-1-SP (Fig. 7) e adjacentes, observa-se que até o final do Jurássico os arenitos que constituem a Formação Rio Bonito estiveram soterrados a profundidades inferiores a $1500 \mathrm{~m}$. Os gráficos da história de soterramento obtidos em poços em que a Formação Rio Bonito encontra-se em maiores profundidades evidenciam que essa unidade atingiu o estágio mesodiagenético no Permiano (Fig. 8). Nestes poços a evolução da história de soterramento mostra que ao atingir profundidade próxima a $2000 \mathrm{~m}$, a Formação Rio Bonito permaneceu sob estas condições diagenéticas durante o Triássico, Jurássico e parte do Cretáceo. Após o Cretáceo a subsidência da Bacia do Paraná foi acentuada pela sobrecarga decorrente do magmatismo e as seqüências que compõem a Formação Rio Bonito alcançaram profundidades próximas a $4.000 \mathrm{~m}$ nas porções mais profundas da bacia.

Os estágios eodiagenético e mesodiagenético dos arenitos da Formação Rio Bonito foram relacionados a uma curva de soterramento obtida pela modelagem da história de subsidência do poço 1-RO-1-PR (Fig. 9). Calcita, siderita, pirita e caolinita ocorrem no estágio eodiagenético, antes de substancial compactação e parecem ter desempenhado um importante papel na preservação do arcabouço. Porém, quando ocorrem nos limites de parassequêcia ou superfícies deposicionais podem formar barreiras de fluxo e compartimentar os reservatórios (Ketzer et al. 2003).

As alterações mesodiagenéticas referem-se a condições de soterramento efetivo a partir de $2000 \mathrm{~m}$ até cerca de $6000 \mathrm{~m}$ de profundidade e temperatura entre $70^{\circ} \mathrm{C}$ a $200^{\circ} \mathrm{C}$. Na mesodiagênese a redução da porosidade nos arenitos da Formação Rio Bonito, relaciona-se à cimentação por anquerita, calcita, clorita, ilita $\mathrm{e}$ quartzo, porém a ocorrências desses constituintes não foi relacionada a um trato de sistema específico.

A precipitação de anquerita é relacionada ao soterramento efetivo e temperatura entre 60 e $145^{\circ} \mathrm{C}$. A formação de clorita é atribuída à transformação de argilas ricas em ferro sob temperatura superior a $70^{\circ} \mathrm{C}$ e profundidade de soterramento a partir de $2000 \mathrm{~m}$. Ilita forma-se sob temperatura superior a $70^{\circ} \mathrm{C}$ e a partir de $130{ }^{\circ} \mathrm{C}$ a sua distribuição torna-se pervasiva (Morad et al., 1990; Giles et al., 1992). Os crescimentos sintaxiais de quartzo formam-se à temperatura entre $90 \mathrm{a}$ $130{ }^{\circ} \mathrm{C}$ e profundidade em torno de $3000 \mathrm{~m}$, durante a mesodiagênese. As condições para precipitação de anquerita, clorita quartzo e ilita foram verificadas a partir do Permiano nos poços onde a Formação Rio Bonito encontra-se em maior profundidade de soterramento.

Nos poços da porção central da bacia a profundidade máxima de soterramento da Formação Rio Bonito foi de aproximadamente $3000 \mathrm{~m}$, que corresponde à temperatura próxima a $110^{\circ} \mathrm{C}$. Estas condições implicam em modificações mesodiagenéticas, tais como compactação química, reações de transformação de argilominerais e 


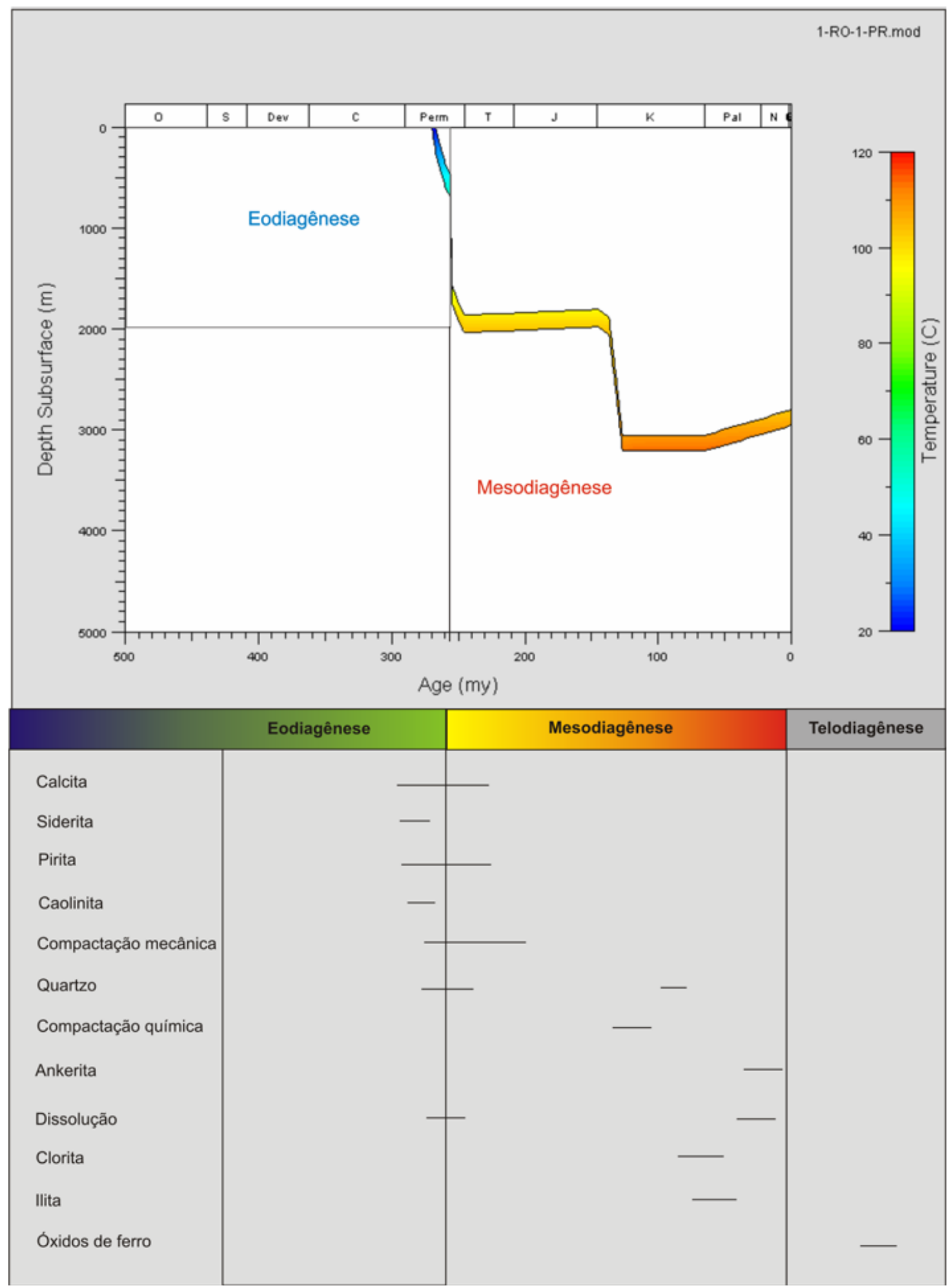

Figura 9 - Distribuição dos constituintes diagenéticos nos arenitos da Formação Rio Bonito e curva de temperatura obtida com base em dados estratigráficos do Poço 1-RO-1-PR.

cimentação de quartzo, apontados como principais processos que atuam no sentido de reduzir o espaço poroso e conexão entre os poros. Nos poços onde a Formação Rio Bonito encontra-se a profundidade de soterramento inferior a $3000 \mathrm{~m}$ a temperatura corresponde a aproximadamente $90{ }^{\circ} \mathrm{C}$. Nesses casos, espera-se que os processos mesodiagenéticos, principalmente a compactação quí- mica e desenvolvimento de cimentação por sílica sejam menos efetivos na redução do espaço poroso.

IMPACTO NA QUALIDADE DOS RESERVATÓRIOS O registro sedimentar da Formação Rio Bonito, observado no poço 2-CS-1-PR e correlatos, inicia com depósitos característicos do trato de sistema de 
mar baixo, sucedida pelas associações de fácies que compõe o trato de sistemas transgressivo e culmina com os depósitos do trato de sistemas de mar alto (Fig. 10). As associações de fácies identificadas possuem condições permoporosas com potencial para armazenar fluidos, porém as unidades de fluxo são compartimentadas pela ocorrência de fácies pelíticas e camadas de carvão. Com os dados de perfil sônico é possível verificar as diferenças de porosidade, bem como a influência dos limites de paraseqüências, superfície transgressiva e superfície de inundação máxima no controle da permoporosidade (Fig. 10).

No trato de sistemas de mar baixo os principais reservatórios consistem em arenitos de depósitos de preenchimento de vales incisos (associações de fácies 1 e 2 - A1 e A2) (Zacarias, 2004), depósitos de leques aluviais e depósitos flúvio-deltáicos (Holz 2003). A associação de fácies 1 é constituída por arenitos feldspáti- cos classificados como subarcóseos finos a grossos com padrão textural de granodecrescência ascendente. Os reservatórios arenosos caracterizam-se por baixa a moderada qualidade devido à seleção pobre a moderada, intercalações de camadas pelíticas e baixa continuidade lateral das camadas. Nesses arenitos a porosidade média é de $6,6 \%$ (porosidade mínima $=4,57$ e porosidade máxima $=7,73$ ). A associação de fácies 2 é constituída por arenitos médios a muito grossos com clastos de argila e pirita. O potencial para armazenagem de fluidos nessa unidade depende da continuidade lateral e espessura das camadas. Porém, as freqüentes intercalações pelíticas observadas em afloramento e perfis de poços comprometem sua qualidade. A porosidade média nesse intervalo é de $2,73 \%$ (porosidade mínima $=0,5 \%$ e porosidade máxima $=6,15 \%$ ).

Os reservatórios do trato de sistemas transgressivos são caracterizados por depósitos de canais fluviais,

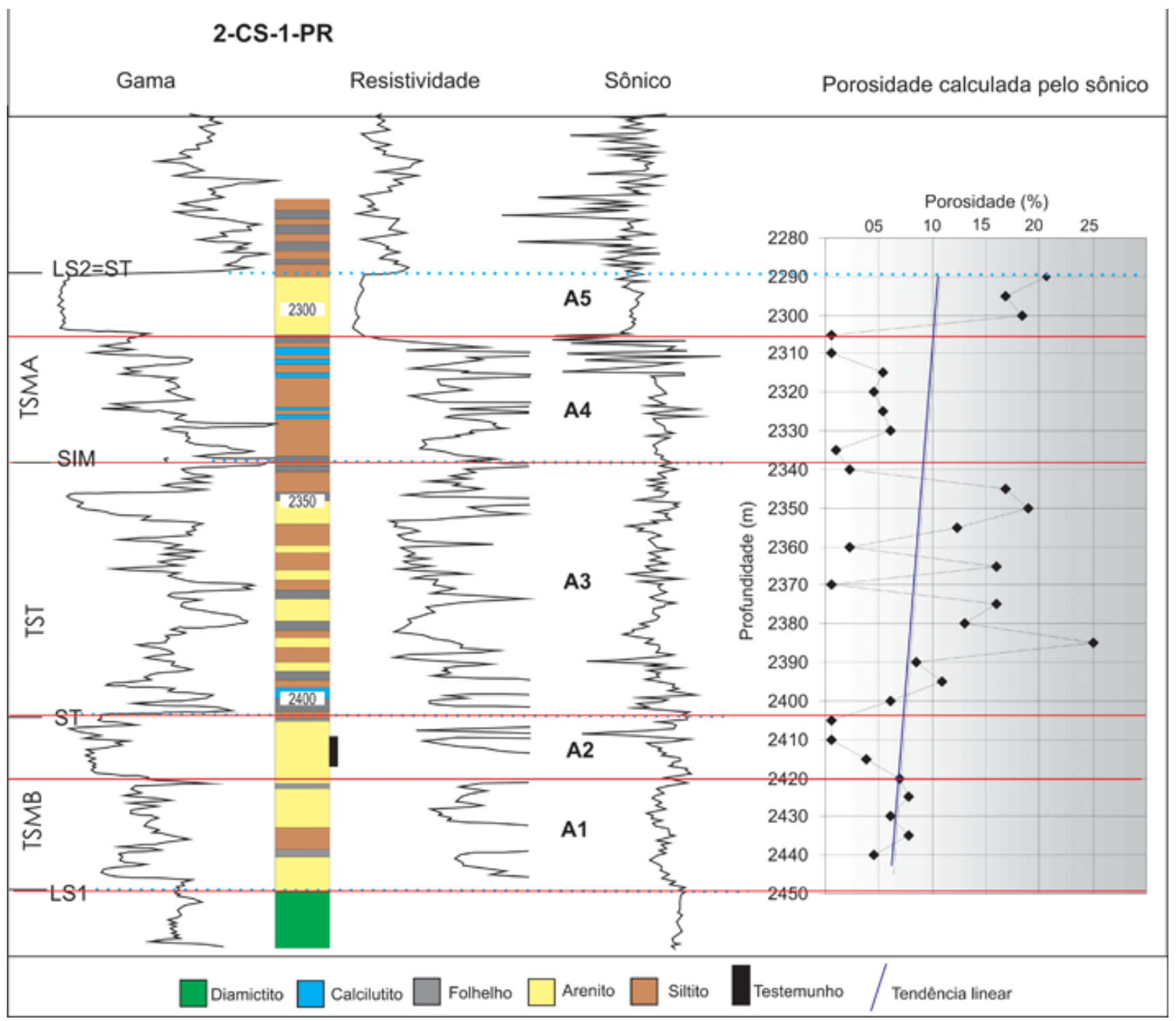

Figura 10 - Distribuição da porosidade da Formação Rio Bonito no poço 2-CS-1-PR. (TSMB: trato de mar baixo, TST: trato transgressivo, TSMA: trato de mar alto, LS: limites de seqüencias, ST: superfícies transgressivas e SIM: superfície de inundação máxima). 
canais de maré e de ilhas barreiras (Associação de fácies 3 - A3) e depósitos de barras de desembocadura, ilhas barreiras e deltas de maré de enchente (porção inferior da associação de fácies 4 - A4). Na associação de fácies 3 predominam lamitos intercalados com camadas pouco espessas de arenitos finos a muito finos, arenitos médios a grossos e níveis de conglomerado maciços, com porosidade média de $12,7 \%$ (porosidade mínima $=0,5$ e porosidade máxima $=25,0$ ). A porção inferior da associação de fácies 4 é constituída por siltitos e arenitos finos a muito finos intercalados com camadas de calcário argiloso com porosidade porosidade média de $3,2 \%$ (porosidade mínima $=0,5 \%$; porosidade máxima $=6,15 \%$ ).

Depósitos marinho rasos de plataforma e barras litorâneas da porção superior da Associação de fácies 4 e Associação de fácies 5, constituem os depósitos do trato de sistemas de mar alto. Na associação de fácies 5 ocorrem arenitos médios a finos, com baixa proporção de argila, boa seleção e constituídos essencialmente por quartzo e cimentação carbonática e constituem reservatórios de moderada a alta qualidade. A baixa argilosidade é bem marcada na resposta dos perfis de raios gama e a porosidade média obtida nesse intervalo é de $18,6 \%$ (porosidade mínima $=16,85$ e porosidade máxima $=20,6$ ). Os elevados valores de porosidade são evidentes no perfil sônico, principalmente quando comparados com os resultados obtidos nas demais associações de fácies (Fig. 10). Com a modelagem da história de soterramento da Formação Rio Bonito obteve-se valores de porosidade em torno de $20 \%$ em arenitos soterrados à profundidade de $3.000 \mathrm{~m}$.

A cimentação eodiagenética exerceu controle da porosidade e compartimentou os reservatórios da Formação Rio Bonito. Os cimentos eodiagenéticos foram significativos na redução de porosidade, principalmente em arenitos do trato de sistemas transgressivos. Arenitos localizados próximo aos limites de paraseqüências contendo camadas de carvão apresentam porosidade inferior a $1 \%$ devido a extensiva cimentação por calcita.

A redução da porosidade na mesodiagênese relaciona-se à cimentação por anquerita, clorita, quartzo e ilita. A precipitação de anquerita ocorre sob temperatura superior a $130^{\circ} \mathrm{C}$. A formação de clorita é atribuída à transformação de argilas ricas em ferro sob temperatura superior a $70^{\circ} \mathrm{C}$ e profundidade de soterramento a partir de $2000 \mathrm{~m}$. Crescimentos sintaxiais de quartzo são formados à temperatura entre 90 a $130^{\circ} \mathrm{C}$ e profundidade em torno de 3000m (Giles et al.,1992). Ilita ocorre sob temperatura superior a $70^{\circ} \mathrm{C}$, tornando-se pervasiva a partir de $130{ }^{\circ} \mathrm{C}$ (Morad et al., 1990; Giles et al., 1992).

$\mathrm{O}$ fluxo de fluidos meteóricos em seqüências siliciclásticas que já haviam sido submetidas a condições de soterramento efetivo, implica em modificações telodiagenéticas, que inclui a dissolução de minerais, em geral de feldspatos, fragmentos líticos e cimentos carbonáticos. Após a dissolução de constituintes instáveis ocorre a precipitação de novos cimentos, influenciada pela mudança das condições geoquímicas. Na Formação Rio Bonito a dissolução de constituintes instáveis, tais como cimentos carbonáticos eodiagenéticos representou um aspecto positivo para geração de porosidade. Este processo foi acentuado provavelmente, pela ação de ácidos orgânicos liberados durante a fase inicial de maturação da matéria orgânica das rochas geradoras da bacia (França \& Potter, 1989). Esta fase corresponde do Neojurássico ao Eocretáceo, quando a Bacia do Paraná foi afetada por uma anomalia térmica regional, decorrente do processo de abertura do oceano Atlântico, que resultou em nova fase de subsidência. Neste período os depósitos que ainda estavam sob influência de fluxos meteóricos, foram submetidos a condições de soterramento mesodiagenético.

A avaliação da influência da cimentação e da compactação na redução do espaço poroso indica que a compactação precoce foi mais importante que a cimentação, na redução da porosidade. Porém em algumas amostras observa-se que a cimentação precoce pode ter influência na preservação do espaço intergranular (Fig. 11). Os índices de fechamento ou de proximidade mostram que o empacotamento dos arenitos é normal $(40<\mathrm{P}<55)$ e algumas vezes é fechado ( $\mathrm{P}>55)$. A redução de porosidade é relacionada principalmente à compactação mecânica, que propiciou a deformação de intraclastos argilosos, geração de pseudomatriz e deformação de minerais micáceos. A porosidade secundária gerada pela dissolução de grãos instáveis e de cimentos aparentemente contribui para ampliação do espaço poroso. O maior problema é que os poros gerados por dissolução são frequentemente isolados, o que dificulta sua conexão.

CONCLUSÕES Os arenitos que compõe a Formação Rio Bonito foram cimentados por pirita, calcita, siderita e caolinita durante a eodiagênese. Os constituintes eodiagenéticos ocorrem preferencialmente próximos aos limites de parasseqüências, associados à camadas de carvão. Os arenitos do trato de sistemas de mar baixo apresentam maior percentual de caolinita atribuído à exposição a fluidos meteóricos durante a eodiagênese. Condições climáticas úmidas durante a deposição favorecem o fluxo de fluidos meteóricos e promovem a dissolução de feldspatos e micas e favorecem à formação de caolinita.

Os principais constituintes diagenéticos relacionados à mesodiagênese foram anquerita, clorita, crescimentos sintaxiais de quartzo e illita. A correlação entre a distribuição de anquerita, clorita e illita e as seqüências deposicionais não é muito evidente. Em arenitos constituídos predominantemente por quartzo, a cimentação por sílica no estágio mesodiagenético foi aparentemente influenciada pela distribuição das alterações eodiagenéticas e predomina em arenitos com pouca influência de cimentação carbonática, depositados sob condições marinha rasas.

A profundidade máxima de soterramento da Formação Rio Bonito é de aproximadamente $4000 \mathrm{~m}$, que corresponde à temperatura próxima a $120^{\circ} \mathrm{C}$. Estas condições implicam em modificações mesodiagenéticas, tais como compactação química, reações de transformação de argilominerais, cimentação de quartzo e alteração térmica da matéria orgânica. Com a modelagem da história de soterramento, considerando a idade, seleção e profundidade, os resultados obtidos para os arenitos 


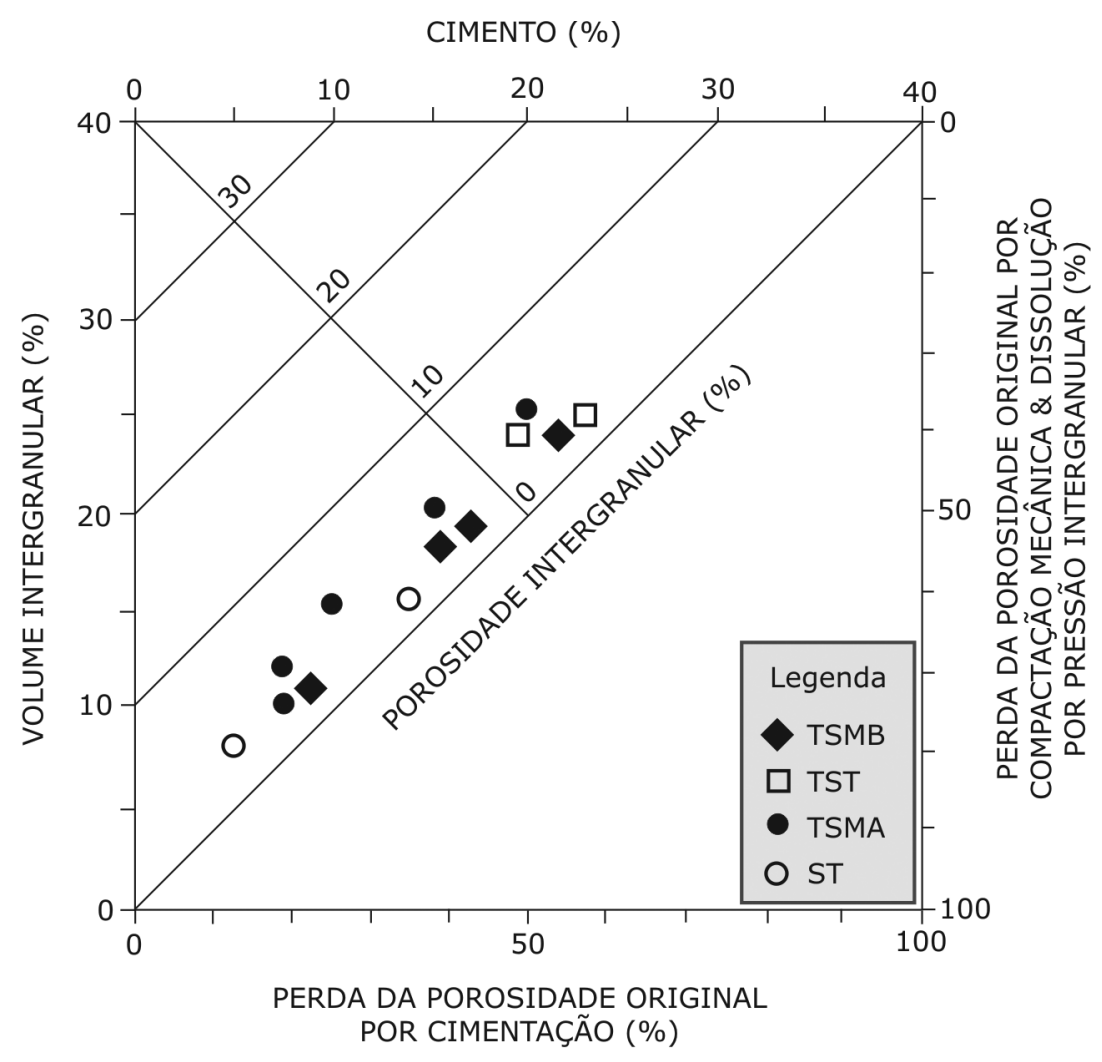

Figura 11 - Diagrama para avaliação da importância relativa da cimentação e da compactação na redução da porosidade (Houseknecht 1987). As amostras referem-se ao TSMB (Trato de sistemas de mar baixo), TST (Trato de sistemas transgressivo), TSMA (Trato de sistemas de mar alto) e ST (Superficie transgressiva).

que compõem a Formação Rio Bonito evidenciam que a porosidade na profundidade de $3.000 \mathrm{~m}$ de soterramento situa-se em torno de $20 \%$. Porém variações importantes de porosidade são controladas pela distribuição de fácies sedimentares. Apesar da importância da compactação na redução da porosidade, destaca-se que a cimentação precoce foi um fator positivo na preservação do arcabouço dos arenitos da Formação Rio Bonito.
Agradecimentos À PETROBRAS - Petróleo Brasileiro S/A por intermédio do PROFEX, Programa Tecnológico em Fronteiras Exploratórias, em conjunto com a FINEP - Financiadora de Estudos e Projetos do Governo Brasileiro pelo apoio ao Projeto SPHERA Simulação de Processos Hidrodinâmicos em Reservatórios Análogos na Bacia do Paraná - À UFPR pelo apoio institucional.

\section{Referências}

Anjos S.M.C. 1995. Análise de imagens no estudo do sistema poroso de rochas reservatório. Boletim Geociências Petrobrás, 9 (2/4):157-173.

Beard D.C. \& Weyl P.K. 1973. Influence of texture on porosity and permeability of unconsolidated sand. American Association of Petroleum Geologists, Bulletin, 57:349-369.

Bjørkum P.A. \& Gjesvik N. 1988. An isochemical model for formation of autthigenic kaolinite, k-feldpar and illite in sediments. Journal of Sedimentary Petrology, 58:506511.

Ehrlich R., Kennedy S.K., Crabtree S.J., Cannon R.L. 1984. Photographic image analysis, I: Analysis of reservoir pore complexes. Journal of Sedimentary Petrology,
54:1365-1378.

Folk R.L. 1968. Petrology of sedimentary rocks. Austin, TX: Hemphill, 107p.

França A.B. \& Potter P.E. 1989. Estratigrafia, ambiente deposicional do Grupo Itararé (Permocarbonífero), Bacia do Paraná (Parte 2). Boletim Geociências Petrobrás, 3:17-28.

Giles M.R., Stevenson S., Martin S.V. 1992. The reservoir properties and diagenesis of the Brent Group: a regional perspective. In: Morton A.C., Haszeldine R.S., Giles M.R., Brown S. (eds.) Geology of the Brent Group. Special Publications of the Geological Society of London, 61:289-327.

Holz M. 1998. The Eo-Permian coal seams of the Paraná 
basin in southernmost Brazil: an analysis of the depositional conditions using sequence stratigraphic concepts. International Journal of Coal Geology, 36(12):141-163.

Holz M. 1999. Early Permian sequence stratigraphy and the palaeophysiographic evolution of the Paraná basin in southernmost Brasil. Journal of African Earth Sciences, 29(1):51-61.

Holz M., Vieira P.E., Kalkreuth W. 2002. The Early Permian coal-bearing sucession of the Paraná basin in southernmost Brazil: depositional model and sequence stratigraphy. Revista Brasileira de Geociências, 30(3):420-422.

Holz M. 2003. Sequence stratigraphy of a lagoonal estuary system - an example from the lower Permian Rio Bonito Formation, Paraná Basin, Brazil. Sedimentary Geology, 162:305-331.

Houseknecht D.W. 1987. Assessing the relative importance of compaction processes and cementation to reduction of porosity in sandstones. American Association of Petroleum Geologists, Bulletin, 71:633-642.

Ketzer J. M., Holz M. Morad S., Al-Aasm I.S. 2003. Sequence stratigraphic controls on the origin and distribution of diagenetic alterations in paralic sandstones: evidence from the Rio Bonito Formation (early Permian), Southern Brazil. Sedimentology, 50: 855-877.

Lopes R.C. \& Lavina E.L.C. 2001. Estratigrafia de Seqüências nas formações Rio Bonito e Palermo (Bacia do Paraná), na região carbonífera do Jacuí, RS. In: Ribeiro S.H.J.P. (ed.) Estratigrafia de Seqüências - Fundamentos e Aplicações. EDUNISINOS, p. 391-419.

Medeiros R.A. \& Thomas Filho A. 1973. Fácies e ambientes deposicionais da Formação Rio Bonito. In: SBG, Congresso Brasileiro de Geologia, 27, Aracaju, Anais, 3:3-12.

Milani E.J. 1997. Evolução tectono-estratigráfica da Bacia do Paraná e seu relacionamento com a geodinâmica fanerozóica do Gonduana Sul-Ocidental. Tese de Doutoramento, Instituto de Geociências, Universidade Federal do Rio Grande do Sul, Porto Alegre.

Milani E.J. 2004. Comentários sobre a origem e evolução tectônica da Bacia do Paraná. In: Mantesso Neto V., Bartorelli A., Carneiro C.D.R., Brito Neves B.B. (eds.) Geologia do Continente Sul-Americano: Evolução da Obra de Fernando Flávio Marques de Almeida. São Paulo: Editora Beca, p.265-279.

Morad S., Al-Aasm I.S., Ramseyer K., Marfil R., Aldahan A.A. 1990. Diagenesis of carbonate cements in PermoTriassic sandstones from the Iberian Range, Spain; evidence from chemical and stable isotopes. Sedimentary Geology, 67:281-295.

Morad S., Ketzer J.M., De Ros L.F. 2000. Spatial and temporal distribution of diagenetic alterations in siliciclastic rocks: implications for mass transfer in sedimentary basins. Sedimentology, 47:1-27.

Schmid S., Worden R.H., Fisher Q.J. 2003. The origin and regional distribution of dolomite cement in sandstones from a Triassic dry river system, Corrib Field, offshore west of Ireland. Journal of Geochemical Exploration, 78(9):475-479.

Schneider R.L., Mühlmann H., Tommasi E., Medeiros R.A., Daemon R., Nogueira A.A. 1974. Revisão estratigráfica da Bacia do Paraná. In: SBG, Congresso Brasileiro de Geologia, 28, Porto Alegre, Anais, 1:41-65.

Welton J.E. 1984. SEPM Petrology Atlas. Methods in exploration series. Oklahoma, AAPG, Tulsa, 231p.

Zacharias A.A. 2004. Preechimento de vales incisos por associações de fácies estuarinas, Formação Rio Bonito, Nordeste do Paraná. Dissertação de Mestrado. Instituto de Geociências da UNESP, Rio Claro, 99p.

Zalán P.V., Wolff S., Conceição J.C.J., Astolfi M.A.M., Vieira I.S., Appi V.T., Zanotto O.A. 1987. Tectônica e sedimentação da Bacia do Paraná. In: Simpósio Sul Brasileiro de Geologia, 3, Curitiba, Atas, 1:441-477.

Zalán P.V., Wolff S., Astolfi M.A.M., Vieira I.S., Conceição J.C.J., Appi V.T., Neto E.V.S., Cerqueira J.R., Marques A. 1990. The Paraná Basin, Brazil. Tulsa: American Association of Petroleum Geologists, Bulletin. Memoir 51:681-708.

Manuscrito ID 13646

Submetido em 16 de março de 2009 Aceito em 14 de agosto de 2009 